\title{
Potocki-Shaffer Syndrome
}

National Cancer Institute

\section{Source}

National Cancer Institute. Potocki-Shaffer Syndrome. NCI Thesaurus. Code C75456.

A very rare genetic syndrome caused by deletions on the proximal short arm of

chromosome 11. It is characterized by the presence of multiple exostoses and enlarged parietal foramina. 